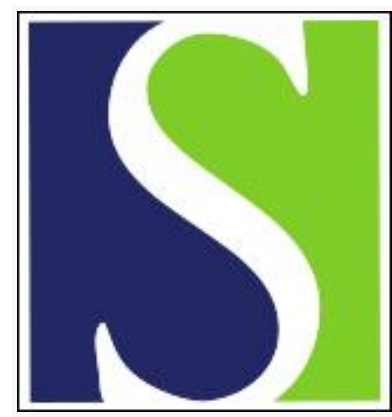

Scand J Work Environ Health 2014;40(6):639-648

https://doi.org/10.5271/sjweh.3452

Published online: 27 Aug 2014, Issue date: 01 Nov 2014

Exposure to psychosocial job strain during pregnancy and odds of asthma and atopic dermatitis among 7-year old children - a prospective cohort study

by Larsen $A D$, Schlünssen V, Christensen BH, Bonde JP, Obel C, Thulstrup AM, Hannerz H, Hougaard KS

Literature suggests a relationship between maternal stress exposure and risk of asthma and atopic dermatitis (AD) among children; so far no studies have focused on maternal job strain. Based on the prospective Danish National Birth Cohort, results show: maternal exposure to high strain jobs was associated with $A D$, whereas active jobs were associated with asthma among 7-year old children.

Affiliation: National Research Centre for the Working Environment, Lersoe Parkallé 105, DK-2100 Copenhagen, Denmark. adl@nrcwe.dk

The following articles refer to this text: 2019;45(2):174-182;

2021;47(7):550-560

Key terms: allergic disease; asthma; atopic dermatitis; birth cohort; children; Danish National Birth Cohort; exposure; high demand; job control; job demand; job strain; low control; offspring; pregnancy; prenatal stress; psychosocial; psychosocial job strain

This article in PubMed: www.ncbi.nlm.nih.gov/pubmed/25162986

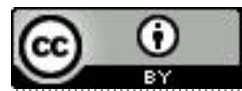




\title{
Exposure to psychosocial job strain during pregnancy and odds of asthma and atopic dermatitis among 7-year old children - a prospective cohort study
}

\author{
by Ann Dyreborg Larsen, PhD, 1, 2 Vivi Schlünssen, PhD, 2, ${ }^{3}$ Berit Hvass Christensen, PhD, 2, 3 Jens Peter \\ Bonde, DMSc, ${ }^{4}$ Carsten Obel, PhD, ${ }^{3}$ Ane Marie Thulstrup, PhD, ${ }^{2}$ Harald Hannerz, PhD, ${ }^{1}$ Karin Sørig \\ Hougaard, $P h D^{1}$
}

\begin{abstract}
Larsen AD, Schlünssen V, Christensen BH, Bonde JP, Obel C, Thulstrup AM, Hannerz H, Haugaard KS. Exposure to psychosocial job strain during pregnancy and odds of asthma and atopic dermatitis among 7-year old children - a prospective cohort study. Scand J Work Environ Health. 2014;40(6):639-648. doi:10.5271/sjweh.3452
\end{abstract}

\begin{abstract}
Objectives Few epidemiological studies have studied maternal stress exposure during pregnancy and odds of asthma and atopic dermatitis (AD) among offspring, and none have extended the focus to psychosocial job strain. The aim of this study was to assess the association between maternal job strain during pregnancy and asthma as well as AD among 7-year-old children.
\end{abstract}

Methods The study is based on the Danish National Birth Cohort and includes prospective data from 32104 pregnancies. Job strain was assessed early in pregnancy by use of two questions on demands and control. We categorized participants into four job strain categories: low strain (low demands, high control), active (high demands, high control), passive (low demands, low control), and high strain (high demands, low control). Information on asthma and AD until age seven was collected using maternal self-report. Multinomial logistic regression models were used to estimate odds ratios (OR) with $95 \%$ confidence intervals $(95 \% \mathrm{CI})$ adjusted for several covariates.

Results Maternal exposure to self-reported high strain during pregnancy was associated with $15 \%$ higher odds of atopic dermatitis among 7-year-old children $\left(\mathrm{OR}_{\text {adj }} 1.15,95 \%\right.$ CI 1.02-1.31). Furthermore, an association between the active jobs and asthma among 7-year-old children was found ( $\left.\mathrm{OR}_{\mathrm{adj}} 1.13,95 \% \mathrm{CI} 1.03-1.24\right)$.

Conclusion Maternal exposure to high strain and active jobs during pregnancy was associated with asthma and atopic dermatitis among 7-year-old children.

Key terms allergic disease; birth cohort; high demand; low control; prenatal stress.

Asthma is one of the most prevalent chronic diseases worldwide with more than 300 million people affected. Likewise, atopic dermatitis (AD) is a common disorder with a lifetime prevalence of $15-20 \%(1,2)$. Recent studies show increasing prevalence of asthma and $\mathrm{AD}$ in Western countries including Denmark (3-5). Hence, among Danish children, the self-reported number of children with asthma rose from $5.3 \%$ in 1986 to $11.7 \%$ in 2001 (6) and from $17.3 \%$ to $27.3 \%$ for $\mathrm{AD}$ during the same period (5).

It has been demonstrated that immune development during fetal growth is altered among asthmatic children $(7,8)$, and adverse programming of immune function may in part occur due to non-constitutive factors such as maternal lifestyle and environmental factors. Several factors have been proposed to contribute to the increasing incidence of asthma and $\mathrm{AD}$ [eg, maternal smoking (9), alcohol consumption (10), eating habits $(11,12)$, obesity (13), and work environment $(14,15)]$. Also maternal stress has been suggested to interfere with fetal immune development $(16,17)$. Prenatal stress has been associated with elevated IgE (immunoglobulin E) in cord blood and alterations in innate and adaptive immune responses as indexed by stimulated cord blood cytokine responses $(18,19)$ and increased risk of childhood eczema (20). This opens the possibility of early programing, altered neonatal immunity and propensity to develop asthma and AD. Only a few epidemiological

1 National Research Centre for the Working Environment, Copenhagen, Denmark.

2 Danish Ramazzini Centre, Department of Occupational Medicine, Aarhus University Hospital, Aarhus, Denmark.

3 Department of Public Health, Section for Environment, Occupation and Health, Danish Ramazzini Centre Aarhus University, Aarhus, Denmark.

4 Department of Occupational and Environmental Medicine, Copenhagen University Hospital Bispebjerg, Copenhagen, Denmark.

Correspondence to: Ann Dyreborg Larsen, National Research Centre for the Working Environment, Lersoe Parkallé 105, DK-2100 Copenhagen, Denmark. [E-mail: adl@nrcwe.dk] 
studies have studied maternal stress exposure during pregnancy and risk of asthma and $\mathrm{AD}$ among offspring (21-25), but little is known about the effects of psychosocial job strain.

The aim of this study was to assess the association between maternal psychosocial job strain during pregnancy and asthma and AD among seven-year old children. The study is conducted in the Danish National Birth Cohort (DNBC). We hypothesized that children of women exposed to high job strain during pregnancy have increased risk of AD and asthma. The combination of high demands and low control is of primary interest as it predicts mental strain according to the Job Strain Model (26).

\section{Methods}

The DNBC was established in 1996 and provides prospective data of more than 100000 pregnancies and their offspring in Denmark. Participation implied interviews based on questionnaires, twice during pregnancy and three times after birth. Further information on the structure and aim of the DNBC can be found elsewhere (27).

Information on the woman's psychosocial work environment, lifestyle, and course of the pregnancy were obtained from the first and second interview planned to take place at weeks $12-16$ and 30-32 of gestation, respectively. We had data on $\mathrm{AD}$ from the fourth and fifth questionnaire, when the child was 18 months and seven years of age, respectively. Information on asthma was obtained from the fifth questionnaire, ie, when the child was seven years old.

In total 100418 pregnancies were included in the DNBC, but our final study population in this study only included 32271 pregnancies. Firstly, 3519 women did not respond to the request for the first interview and a further 33160 women were not pregnant or working at the time of the first interview. Secondly, we excluded 1962 multiple pregnancies to avoid dependency between participants, and - among women who contributed with more than one pregnancy - we excluded the second sibling to avoid overrepresentation of genes ( $\mathrm{N}=5530$ siblings). Thirdly, 21265 children with no data on asthma and $\mathrm{AD}$ and 250 with no response on exposure to job strain were excluded. Finally we had 2461 missing replies on covariates. The exclusion procedure is described in figure 1. According to the data obtained at the time of the first interview, 56247 mothers were eligible for inclusion in the analysis. Of these 34982 $(62 \%)$ participated in the fifth interview.

\section{Exposure}

From the first telephone interview (median 15 weeks) maternal self-reported data regarding exposure to psychosocial work environment were collected. The ques- tions were: "Do you have too many tasks at your work?" and "Do you have the opportunity to influence your tasks and working conditions?" with the response categories: often, sometimes, and seldom.

The first question is interpreted as a proxy for a demand dimension and the second a control dimension. In Karasek's Job Strain Model, the combination of these dimensions are used to assess psychosocial job strain (28). Based on their answers, the women were divided into four job strain categories related to the dimensions of demand and control: low strain (low demands, high control), active (high demands, high control), passive (low demands, low control), and high strain (high demands, low control).

The combination of high demands and low control is the primary interest of this study as it predicts mental strain according to the Job Strain Model (26). To maximize contrast in exposure, the high-strain group was defined by those who answered "often" to high demands and "seldom" to the question relating to control. This and the other groupings can be seen in figure 2 .

The distribution of answers to the exposure questions can be seen in table 1 .

To estimate the influence of asthmogen exposure at work during pregnancy on the association between psychosocial job strain and the risk of developing asthma and/or AD, supplementary analyses are included. Based on the job exposure matrix developed by Kennedy et al $(14,29)$, with some modifications, three subgroups related to airborne asthmogen exposure was constructed. The three subgroups were: exposure to (i) high molecular weight agents (eg, veterinarians, gardeners and bakers), (ii) low molecular weight agents (eg, cooks, cleaners, hairdressers, dentistry, manufacturing of dusty products), and (iii) mixed environments (eg, healthcare professionals). Other professions were not included in this analysis.

Furthermore, an additional analysis was made by stratifying on the home environment to crudely check the impact of microbial burden according to the "hygiene hypothesis". Higher living standards with cleaner homes expose children to a lower amount of microbial components (30). This should be particularly important in the first years as the innate immune system is not challenged to suppress the allergenic Th2 immune phenotype. The consequence is a dominance of the Th2 phenotype and thereby a higher risk of developing allergic diseases later in life (31). In the first questionnaire, the women were asked if they lived on a farm with animals; 2105 women replied positively.

\section{Outcome}

Asthma. For definition of childhood asthma, we used validated core questions from the International Study of Asthma and Allergies in Childhood (32) included in 


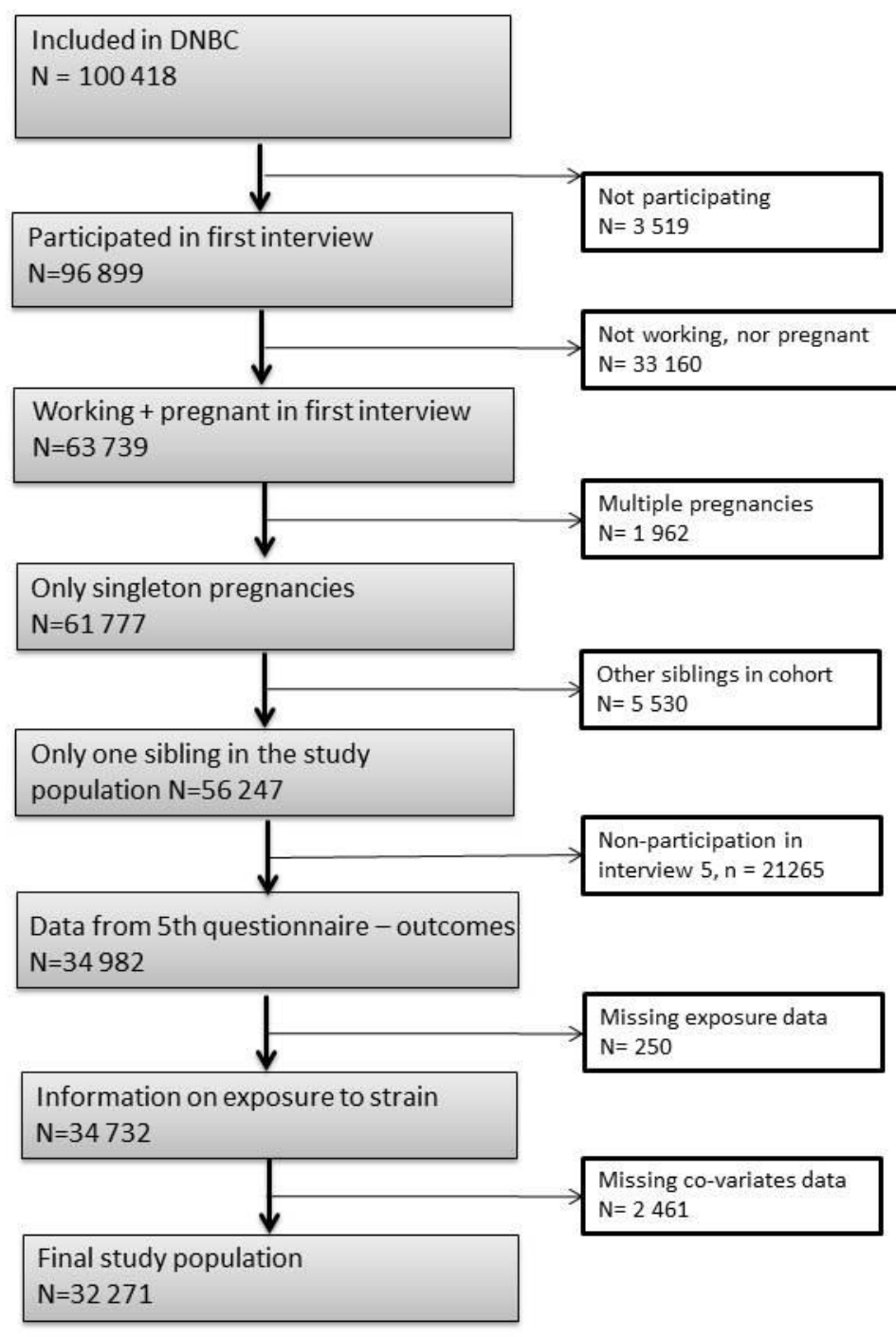

Figure 1. Flowchart describing the inclusion procedures to the study population. The fifth questionnaire is equal to the 7 year follow-up.

the DNBC. A child was considered to have had asthma if the mother responded yes to one or more of the three questions: "Has your child experienced wheezing or whistling in the last 12 months?"; "Has your child ever had asthma?" and "Has your child ever been diagnosed with asthma by a doctor?". Based on the study population with 32270 pregnancies, 4214 (13\%) children had had asthmatic symptoms at seven years of age.

Atopic dermatitis. AD was defined as parental report of "ever AD" (positive response to the question: "Has he/ she had pruritic skin eruption?") or itchy rash in the locations typical for $\mathrm{AD}$ (around eyes, ears, on the neck, elbow, knees and front and back of legs) at 18 months and/or report of a persistent itchy rash in the locations known to be typical for $\mathrm{AD}$ at age seven. In the studied population, $20 \%$ of the children could be defined as having or having had $\mathrm{AD}$ at age seven years.

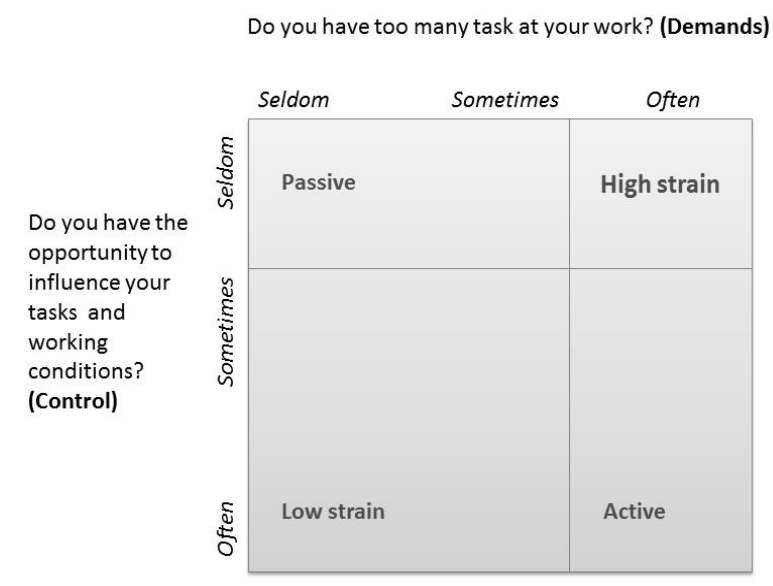

Figure 2. Illustration of the grouping of strain categories used in this study in accordance to the Job Strain Model by Robert Karasek (26), redrawn from (38). 
Table 1. The maternal response to the two exposure questions presented for each response category (often, sometimes, seldom).

\begin{tabular}{|c|c|c|c|c|c|c|}
\hline \multirow{3}{*}{$\begin{array}{l}\text { Do you have the } \\
\text { opportunity to } \\
\text { influence your } \\
\text { tasks and working } \\
\text { conditions? }\end{array}$} & \multicolumn{6}{|c|}{ Do you have too many tasks at work? } \\
\hline & \multicolumn{2}{|c|}{ Seldom } & \multicolumn{2}{|c|}{ Sometimes } & \multicolumn{2}{|c|}{ Often } \\
\hline & $\mathrm{N}$ & $\%$ & $\mathrm{~N}$ & $\%$ & $\mathrm{~N}$ & $\%$ \\
\hline Seldom & 974 & 3.02 & 1763 & 5.46 & 2028 & 6.28 \\
\hline Sometimes & 1578 & 4.85 & 4989 & 15.46 & 3436 & 10.65 \\
\hline Often & 5242 & 16.24 & 8414 & 26.07 & 3847 & 11.92 \\
\hline
\end{tabular}

\section{Covariates}

All covariates were chosen a priori based on the literature in the field and were primarily obtained in the first interview: maternal age $(<25,25-29,30-34, \geq 35$ years $)$, parity $(0,1, \geq 2$ births), maternal body mass index (BMI $15-18.4,18.5-24.9,25-29.9$, and $\left.30.0-49.9 \mathrm{~kg} / \mathrm{m}^{2}\right)$, smoking $(0,<10$, and $>10$ cigarettes a day), alcohol intake $(0,<1,1-2$, and $>2$ units of alcohol per week), gestational age at interview $(<16,16-22,>22$ gestational weeks), furry animal ownership during pregnancy (yes/ no), maternal atopic disposition (ever reported asthma/ rhinitis/AD). From the second interview, the following were gathered: use of pain killers (yes/no), antibiotics (yes/no), and folic acid (yes/no); and from the Danish Birth Registry: sex, birth weight and gestational age at birth [for calculation of small-for-gestational-age (SGA), defined as the $10 \%$ lightest babies for each week and sex within the whole DNBC population].

\section{Statistical analysis}

We tested the association between the four job strain groups (high strain, active, and passive versus low strain) and atopic problems. Using multinomial logistic regression models, we estimated the odds ratios (OR) with $95 \%$ confidence intervals $(95 \% \mathrm{CI})$ of having asthma as well as $\mathrm{AD}$ and either $\mathrm{AD}$ or asthma alone relative to neither asthma nor $\mathrm{AD}$.

Analyses were conducted in the statistical package SAS version 9.3 (SAS Institute, Cary, NC, USA) with the procedure "proc logistic". A likelihood ratio was used to test the overall null-hypothesis in the analysis that assumes the outcome to be independent of job-strain.

\section{Results}

Of 32271 children, 1301 (4.0\%) had both asthma and $\mathrm{AD}, 2913$ (9.0\%) had asthma without AD, 5240 (16.2\%) had AD without asthma, and 22816 (70.7\%) had neither asthma nor AD. Table 2 shows the demographic characteristics of the four exposure groups. About $50 \%$ of the women gave their first interview before week 16 of pregnancy. The women were around 25-34 years of age [median $30.4(16-47)$ years]. The low-strain group had the lowest percentage of maternal atopy. Approximately half of the women were primiparous. The high-strain group had the highest proportions of women with both low and high BMI and the highest percentage of women smoking $>10$ cigarettes per day, but the lowest number of women consuming alcohol during their pregnancy. Folate intake was similar in all exposure groups. The high-strain group had the highest percentage of intake of painkillers and antibiotics and the lowest number of boys compared with the other exposure groups.

Table 3 shows the crude and adjusted results from the analyses on odds of asthma and AD and maternal job strain during pregnancy. The overall log likelihood tests indicated significant associations between job strain and allergic diseases among offspring. Adjustment for covariates did not change these estimates notably. In the crude as well as the adjusted analyses, the association between high strain and the odds of $\mathrm{AD}$ among the children was statistically significantly elevated (OR 1.14, 95\% CI 1.01-1.29; $\mathrm{OR}_{\mathrm{adj}} 1.15,95 \%$ CI $\left.1.02-1.31\right)$. No effects were seen for asthma and AD combined. Furthermore, for women belonging to the active group, the odds of having a child with asthma was elevated statistically

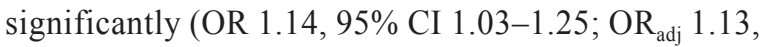
95\% CI 1.03-1.24).

As seen in table 4, the overall P-value was far from significant as the $95 \%$ CI were wide and, for some of the analyses, it was not possible to compute the OR due to the low number of cases. The table should therefore be interpreted with care. It can be noticed that some effect seems to appear from low molecular weight agents in both the high-strain group regarding $\mathrm{AD}\left(\mathrm{OR}_{\mathrm{adj}} 1.53\right.$, 95\% CI 1.07-2.18) and in the active group regarding asthma and $\mathrm{AD}\left(\mathrm{OR}_{\mathrm{adj}} 1.63,95 \%\right.$ CI 1.02-2.62) when looking at the association between airborne asthmogen exposure at work and asthma and $\mathrm{AD}$ in the different job exposure categories.

The second supplementary analysis related to the mother's living environment. High-strain women living in a rural environment with animals had a significantly higher odds of having children with $\mathrm{AD}\left(\mathrm{OR}_{\mathrm{adj}} 1.69\right.$, 95\% CI 1.06-2.71), whereas this association was not statistically significant for high-strain women living in the urban areas $\left(\mathrm{OR}_{\mathrm{adj}} 1.11,95 \% \mathrm{CI} 0.98-1.27\right)$. For the active group, a positive association was found for asthma, but only statistically significant for the urban group (rural: $\mathrm{OR}_{\mathrm{adj}} 1.36,95 \% \mathrm{CI} 0.95-1.96$; urban: $\mathrm{OR}_{\mathrm{adj}}$ $1.11,95 \%$ CI 1.01-1.23). 
Table 2. The four maternal exposure groups of strain and all covariates ( $N=32$ 271)

\begin{tabular}{|c|c|c|c|c|c|c|c|c|}
\hline \multirow[t]{2}{*}{ Characteristics } & \multicolumn{2}{|c|}{ High strain } & \multicolumn{2}{|c|}{ Active } & \multicolumn{2}{|c|}{ Passive } & \multicolumn{2}{|c|}{ Low strain } \\
\hline & $\mathrm{N}$ & $\%$ & $\mathrm{~N}$ & $\%$ & $\mathrm{~N}$ & $\%$ & $\mathrm{~N}$ & $\%$ \\
\hline & 2028 & 6.3 & 7283 & 22.5 & 2737 & 8.5 & 20223 & 62.7 \\
\hline \multicolumn{9}{|l|}{ Maternal age } \\
\hline$<25$ & 156 & 7.7 & 386 & 5.3 & 255 & 9.3 & 1137 & 5.6 \\
\hline $25-29$ & 779 & 38.4 & 2567 & 35.3 & 1075 & 39.3 & 7728 & 38.2 \\
\hline $30-34$ & 797 & 39.3 & 3073 & 42.2 & 1024 & 37.4 & 8118 & 40.1 \\
\hline$>35$ & 296 & 14.6 & 1257 & 17.3 & 382 & 14.0 & 3240 & 16.0 \\
\hline \multicolumn{9}{|l|}{ Maternal atopy } \\
\hline Yes & 389 & 19.2 & 1380 & 19.0 & 539 & 19.7 & 3636 & 18.0 \\
\hline No & 1639 & 80.8 & 5903 & 81.0 & 2198 & 80.3 & 16587 & 82.0 \\
\hline \multicolumn{9}{|l|}{ Parity } \\
\hline 0 births & 940 & 46.4 & 3587 & 49.2 & 1396 & 51.0 & 10599 & 52.4 \\
\hline 1 birth & 745 & 36.7 & 2656 & 36.5 & 940 & 34.4 & 6655 & 32.9 \\
\hline$\geq 2$ births & 343 & 16.9 & 1040 & 14.3 & 400 & 14.6 & 2969 & 14.7 \\
\hline \multicolumn{9}{|c|}{ Body mass index $\left(\mathrm{kg} / \mathrm{m}^{2}\right)$} \\
\hline $15-18.4$ & 82 & 4.0 & 273 & 3.8 & 101 & 3.7 & 789 & 3.9 \\
\hline $18.5-24.9$ & 1368 & 67.5 & 5279 & 72.5 & 1863 & 68.1 & 14422 & 71.3 \\
\hline $25-29.9$ & 417 & 20.6 & 1287 & 17.7 & 573 & 20.9 & 3715 & 18.4 \\
\hline $30-50$ & 161 & 7.9 & 444 & 6.1 & 199 & 7.3 & 1297 & 6.4 \\
\hline \multicolumn{9}{|c|}{ Tobacco (cigarettes/cigars etc) } \\
\hline 0 & 1511 & 74.4 & 5770 & 79.3 & 2084 & 76.2 & 16675 & 82.5 \\
\hline$\leq 10$ & 373 & 13.6 & 1513 & 15.9 & 466 & 17.1 & 2733 & 13.5 \\
\hline$>10$ & 144 & 7.1 & 437 & 4.7 & 186 & 6.7 & 815 & 4.0 \\
\hline \multicolumn{9}{|c|}{ Alcohol (units per week) } \\
\hline 0 & 1159 & 57.2 & 3755 & 51.6 & 1501 & 54.9 & 10443 & 51.6 \\
\hline$<1$ & 320 & 15.8 & 1189 & 16.3 & 468 & 17.1 & 3391 & 16.8 \\
\hline $1-2$ & 460 & 22.7 & 1953 & 26.8 & 670 & 24.5 & 5395 & 26.7 \\
\hline$>2$ & 89 & 4.3 & 386 & 5.3 & 97 & 3.5 & 994 & 4.9 \\
\hline \multicolumn{9}{|l|}{ Folic acid intake } \\
\hline Yes & 510 & 25.2 & 1989 & 27.3 & 670 & 24.5 & 5335 & 26.38 \\
\hline No & 1518 & 74.8 & 5294 & 72.7 & 2066 & 75.5 & 14888 & 73.62 \\
\hline \multicolumn{9}{|l|}{ Painkillers } \\
\hline Yes & 1152 & 56.8 & 3715 & 51.0 & 1437 & 52.5 & 10146 & 50.2 \\
\hline No & 876 & 43.2 & 3568 & 49.0 & 1299 & 47.5 & 10077 & 49.8 \\
\hline \multicolumn{9}{|l|}{ Antibiotics } \\
\hline Yes & 375 & 18.5 & 1321 & 18.1 & 473 & 17.3 & 3371 & 16.7 \\
\hline No & 1653 & 81.5 & 5962 & 81.9 & 2263 & 82.7 & 16852 & 83.3 \\
\hline \multicolumn{9}{|c|}{ Gestational age at interview (weeks) } \\
\hline$<16$ & 1035 & 51.0 & 3438 & 47.2 & 1413 & 51.6 & 9728 & 48.1 \\
\hline$\geq 16$ & 993 & 49.0 & 3845 & 52.8 & 1323 & 48.4 & 10495 & 51.9 \\
\hline \multicolumn{9}{|c|}{ Small for gestational age } \\
\hline No & 1817 & 89.6 & 6671 & 91.6 & 2484 & 90.8 & 18375 & 90.9 \\
\hline Yes & 211 & 10.4 & 612 & 8.4 & 252 & 9.2 & 1848 & 9.1 \\
\hline \multicolumn{9}{|l|}{ Gender } \\
\hline Boy & 999 & 49.3 & 3765 & 51.7 & 1411 & 51.6 & 10371 & 51.3 \\
\hline Girl & 1029 & 50.7 & 3518 & 48.3 & 1325 & 48.4 & 9852 & 48.7 \\
\hline \multicolumn{9}{|c|}{ Furry animal ownership } \\
\hline Yes & 864 & 44.0 & 2836 & 40.3 & 1184 & 45.0 & 8087 & 41.5 \\
\hline No & 1098 & 56.0 & 4200 & 59.7 & 1449 & 55.0 & 11401 & 58.5 \\
\hline
\end{tabular}

\section{Discussion}

\section{Key findings}

We found that maternal exposure to self-reported high job strain during pregnancy was associated with $\mathrm{AD}$ among 7-year-old children. A similar pattern emerged in the sub-analyses on the combined effect of strain and airborne asthmogen exposure at work during pregnancy and in the analyses on rural or urban home environment. The associations between high strain and asthma with or without AD were not significant. Furthermore, we found an association of belonging to the active group and asthma among seven-year-old children.

\section{Previous studies}

As far as we know, maternal job stress during pregnancy has not previously been studied relative to $\mathrm{AD}$ or asthma, apart from one study reporting increased odds of childhood $\mathrm{AD}$ when the mother had reported high work stress (25). Outside work-settings, an associa- 
Table 3. Multinomial logistic regression models testing the odds of child asthma and atopic dermatitis (AD), asthma (but not AD), and AD (but not asthma), compared to no asthma nor AD when exposed to job strain during pregnancy. Bold indicates that the estimates differ statistically significantly from the low strain group [OR=odds ratio; $95 \% \mathrm{Cl}=95 \%$ confidence interval.]

\begin{tabular}{|c|c|c|c|c|c|c|c|c|c|c|c|c|}
\hline \multirow{3}{*}{$\begin{array}{l}\text { Exposure } \\
(N=32271)\end{array}$} & \multicolumn{6}{|c|}{ Crude analysis } & \multicolumn{6}{|c|}{ Adjusted analysis ${ }^{a}$} \\
\hline & \multicolumn{2}{|c|}{$\begin{array}{c}\text { Asthma and AD } \\
\quad(\mathrm{N}=1301)\end{array}$} & \multicolumn{2}{|c|}{$\begin{array}{l}\text { Asthma no AD } \\
\quad(\mathrm{N}=2913)\end{array}$} & \multicolumn{2}{|c|}{$\begin{array}{l}\text { AD no asthma } \\
(\mathrm{N}=5240)\end{array}$} & \multicolumn{2}{|c|}{$\begin{array}{l}\text { Asthma and } A D \\
\qquad(\mathrm{~N}=1301)\end{array}$} & \multicolumn{2}{|c|}{$\begin{array}{l}\text { Asthma no AD } \\
\quad(\mathrm{N}=2913)\end{array}$} & \multicolumn{2}{|c|}{$\begin{array}{c}\text { AD no asthma } \\
(\mathrm{N}=5240)\end{array}$} \\
\hline & OR & $95 \% \mathrm{Cl}$ & OR & $95 \% \mathrm{Cl}$ & OR & $95 \% \mathrm{Cl}$ & OR & $95 \% \mathrm{Cl}$ & OR & $95 \% \mathrm{Cl}$ & OR & $95 \% \mathrm{Cl}$ \\
\hline High strain & 1.15 & $0.92-1.45$ & 1.16 & $0.99-1.35$ & 1.14 & $1.01-1.29$ & 1.11 & $0.88-1.40$ & 1.08 & $0.92-1.27$ & 1.15 & $1.02-1.31$ \\
\hline Active & 1.11 & $0.97-1.27$ & 1.14 & $1.03-1.25$ & 1.08 & $1.00-1.16$ & 1.09 & $0.95-1.25$ & 1.13 & $1.03-1.24$ & 1.07 & $0.99-1.15$ \\
\hline Passive & 1.18 & $0.97-1.43$ & 1.06 & $0.92-1.22$ & 0.93 & $0.83-1.04$ & 1.10 & $0.91-1.34$ & 0.99 & 0.86-1.14 & 0.93 & $0.83-1.04$ \\
\hline Low strain & 1.00 & .. & 1.00 & .. & 1.00 & .. & 1.00 & .. & 1.00 & .. & 1.00 & .. \\
\hline
\end{tabular}

a Adjusted for maternal age, parity, body mass index, smoking, alcohol intake, gestational age at interview, furry animal ownership, maternal atopic disposition, pain killers, antibiotics, folic acid, gender, and small-for-gestational-age.

Table 4. Odds ratios (OR) of child asthma and atopic dermatitis (AD), asthma (but not $A D$ ), and $A D$ (but not asthma), when exposed to psychosocial job strain during pregnancy - divided into subgroups related to the categories of airborne asthmogen exposure at work during pregnancy. ${ }^{\mathrm{a}, \mathrm{b}}$ Bold indicates that the estimates differ statistically significantly from the low strain group. [ $95 \% \mathrm{Cl}=95 \%$ confidence interval.]

\begin{tabular}{|c|c|c|c|c|c|c|c|}
\hline \multirow{2}{*}{$\begin{array}{l}\text { Exposure/outcome } \\
(\mathrm{N}=6250)\end{array}$} & \multirow[t]{2}{*}{ Cases $^{c}$} & \multicolumn{2}{|c|}{ Asthma and AD } & \multicolumn{2}{|c|}{ Asthma no AD } & \multicolumn{2}{|c|}{ AD no asthma } \\
\hline & & OR & $95 \% \mathrm{Cl}$ & OR & $95 \% \mathrm{Cl}$ & $\mathrm{OR}$ & $95 \% \mathrm{Cl}$ \\
\hline \multicolumn{8}{|l|}{ High strain } \\
\hline High molecular & 6 & 5.90 & $0.55-63.32$ & . &.. & 1.21 & $0.30-4.85$ \\
\hline Low molecular & 99 & 1.39 & $0.70-2.77$ & 1.36 & $0.91-2.02$ & 1.53 & $1.07-2.18$ \\
\hline Mixed & 181 & 0.99 & $0.63-1.57$ & 1.12 & $0.82-1.52$ & 1.14 & $0.90-1.44$ \\
\hline \multicolumn{8}{|l|}{ Active } \\
\hline High molecular & 22 & 1.08 & $0.21-5.59$ & 1.36 & $0.48-3.89$ & 0.99 & $0.37-2.67$ \\
\hline Low molecular & 183 & 1.63 & $1.02-2.62$ & 1.11 & $0.82-1.50$ & 0.98 & $0.73-1.30$ \\
\hline Mixed & 596 & 1.11 & $0.82-1.51$ & 1.08 & $0.87-1.34$ & 1.01 & $0.85-1.20$ \\
\hline \multicolumn{8}{|l|}{ Passive } \\
\hline High molecular & 9 & 1.34 & $0.20-9.09$ & 0.25 & $0.05-1.35$ & 0.59 & $0.16-2.10$ \\
\hline Low molecular & 123 & 1.10 & $0.58-2.07$ & 1.36 & $0.97-1.91$ & 1.06 & $0.76-1.48$ \\
\hline Mixed & 161 & 1.01 & $0.66-1.56$ & 0.79 & $0.56-1.10$ & 0.97 & $0.76-1.24$ \\
\hline \multicolumn{8}{|l|}{ Low strain } \\
\hline High molecular & 41 & 1.00 & .. & 1.00 & .. & 1.00 & .. \\
\hline Low molecular & 419 & 1.00 & .. & 1.00 &.$\cdot$ & 1.00 & .. \\
\hline Mixed & 1130 & 1.00 & .. & 1.00 &.. & 1.00 & .. \\
\hline
\end{tabular}

a The low number of participants is due to inclusion of only jobs involving exposure to airborne astmogens.

${ }^{b}$ Adjusted for maternal age, parity, body mass index, smoking, alcohol intake, gestational age at interview, furry animal ownership, maternal atopic disposition, pain killers, antibiotics, folic acid, gender, and small-for-gestational-age.

c Number of participants in each group of asthmogen exposure for each of the strain groups.

tion between maternal psychological stress and odds of eczema in the child has been observed (20). This was confirmed in a study showing associations of both child asthma and $\mathrm{AD}$ with maternal report of stressful life events (mourning, divorce, loss of job) (24). Other studies found associations with asthma in the offspring when the mother had lost a close relative (23) or experienced high levels of anxiety (21). One of the main differences between these and the present study is the definition of the stress exposure variable. Both bereavement and high levels of anxiety may rather be regarded as proxies for severe stress and might not share many similarities with high strain at work.

In the analyses of airborne asthmogens, we anticipated an additive effect of exposure to chemicals and high strain as a review from 2007 describes that stress may enhance the effects of chemical exposures on development of a variety of organ systems (33). Maternal exposure to asthmogens did however not seem to modify the association between job strain and childhood asthma and/or AD. The analysis was under-powered and should be interpreted with care.

The second supplementary analysis stratified by the answer of "yes" or "no" to the question "Do you live on a farm with farm animals?" aimed to investigate crudely the implications of the hygiene hypothesis relative to maternal strain at work. The results are basically similar for the two home environments, indicating that farm animals do not have a big impact on the effect of job strain on childhood allergic disease.

The significant association between active jobs during pregnancy and risk of having children with asthma 
Table 5. Odds ratios (OR) of child asthma and atopic dermatitis, asthma (but not AD), and AD (but not asthma), when exposed to psychosocial job strain during pregnancy - stratified by home environment (farm with animals versus other). Bold indicates that the estimates differ statistically significantly from the low strain group.

\begin{tabular}{|c|c|c|c|c|c|c|c|}
\hline \multirow{2}{*}{$\begin{array}{l}\text { Exposure/outcome } \\
\left(\mathrm{N}=30156^{\mathrm{a}}\right)\end{array}$} & \multirow[t]{2}{*}{ Cases $^{b}$} & \multicolumn{2}{|c|}{ Asthma and AD } & \multicolumn{2}{|c|}{ Asthma no AD } & \multicolumn{2}{|c|}{ AD no asthma } \\
\hline & & $\mathrm{OR}$ & $95 \% \mathrm{Cl}$ & $\mathrm{OR}$ & $95 \% \mathrm{Cl}$ & $\mathrm{OR}$ & $95 \% \mathrm{Cl}$ \\
\hline \multicolumn{8}{|l|}{ High strain } \\
\hline Farm & 47 & 0.83 & $0.25-2.73$ & 1.67 & $0.96-2.91$ & 1.69 & $1.06-2.71$ \\
\hline Other & 591 & 1.11 & $0.88-1.41$ & 1.04 & $0.88-1.23$ & 1.11 & $0.98-1.27$ \\
\hline \multicolumn{8}{|l|}{ Active } \\
\hline Farm & 124 & 1.62 & $0.95-2.75$ & 1.36 & $0.95-1.96$ & 1.07 & $0.76-1.48$ \\
\hline Other & 2106 & 1.06 & $0.92-1.22$ & 1.11 & $1.01-1.23$ & 1.07 & $0.99-1.15$ \\
\hline \multicolumn{8}{|l|}{ Passive } \\
\hline Farm & 43 & 1.81 & $0.88-3.73$ & 0.79 & $0.42-1.49$ & 1.03 & $0.63-1.70$ \\
\hline Other & 743 & 1.06 & $0.87-1.30$ & 0.99 & $0.86-1.14$ & 0.92 & $0.82-1.03$ \\
\hline \multicolumn{8}{|l|}{ Low strain } \\
\hline Farm & 343 & 1.00 & .. & 1.00 & .. & 1.00 & .. \\
\hline Other & 5454 & 1.00 & .. & 1.00 & .. & 1.00 & .. \\
\hline
\end{tabular}

a 2115 subjects had missing replies to the question regarding home environment. The analysis was adjusted for maternal age, parity, body mass index, smoking, alcohol intake, gestational age at interview, furry animal ownership, maternal atopic disposition, pain killers, antibiotics, folic acid, gender and small-for-gestational-age.

${ }^{\mathrm{b}}$ Cases refer to the number of participants in each group of asthmogen exposure for each of the strain groups.

was unexpected, as we had no a priori hypothesis in regards to the active group. A few studies have previously demonstrated a relationship between the active group and health implications. A Finnish study from Kivimäki et al, showed that the active group were associated with an increased risk of cerebrovascular disease events (CVD) when compared to low strain (34). This is supported by another Finnish study, which looked at high decision authority (part of the control aspect in Karasek's model) and found elevated risks of all-cause, CVD, and alcohol-related mortality. A French study on job strain and masked hypertension found an association of these but only for men (35). A study from the US found an association of job strain and a CVD event. The association was only statistically significant for women working in the high-strain and active group after extended adjustments (36). It has not been possible to find studies looking at asthma as the endpoint when exposed to job strain.

\section{Implications of use of the strain variable}

Two questions were used to categorize the women with respect to job strain and were available in the DNBC on job stress. A similar approach has been used in others studies in the DNBC (37-39). Karasek's job strain model was designed to assess job strain among industrial workers $(26,40)$. It was based on several questions in the Job Content Questionnaire relating to demand and control at work (41). If the measure is imprecise and the misclassification is non-differential this will most likely lead to an underestimation of the associations. It can therefore not be excluded that the reported moderate effects stem from larger effects that are underestimated due to the limited exposure information. As far as we know, no studies have looked at the validity of using global questions in regards to the Job Content Questionnaire and Karasek's model. But Littman et al (42) have compared the use of single-items measure on perceived stress, daily hassles, and life events versus fully validated multi-item instruments. They found that the single-items could be considered reliable with a validity similar to that of longer questionnaires. We hypothesized that, of the four quadrants in the job-strainmodel, high strain would have the greatest impact on fetal programing of the immune system. Unexpectedly, we also observed associations for maternal belonging to the active group as Karasek's theory implies that only workers with high strain are at risk for diseases (43). It is possible, that high strain represents the stressful aspects of repetitive and routine work whereas active jobs covers stress related to control, eg, in managerial jobs. Of note, the high strain and the active groups share the dimension of high demands. Rather than using the original model (28), it has recently been proposed to analyze the demand and control dimensions in the main analyses and include the multiplicative term of high strain included as a covariate (44).

\section{Strengths and limitations}

The study is large, prospective, and includes full information on exposure, outcome and covariates for more than 30000 women and their children and a follow-up of seven years. The prospective design protects against recall bias as the women were asked about their job exposure long before their child developed allergic disease. Further, the statistical methods of multinomial logistic regression, defining the children as either case with asthma and $\mathrm{AD}$, or asthma or $\mathrm{AD}$ alone provides 
the advantage of a "clean" reference group with which the three types of cases can be contrasted.

There are some limitations, however. AD was defined as a combination of maternal reports and confirmation of eczema in locations typical for $\mathrm{AD}$. These questions in the DNBC have been validated (45) and found applicable for use in large-scale epidemiological studies. The questions were supplemented by the presence of eczema at seven years of age to increase the sensitivity maybe at the expense of specificity (14). The questions were validated and standardized in regards to asthma (32). We only included information provided by the mothers, no diagnoses was therefore confirmed or provided directly by a doctor. We can therefore not rule out the risk of non-differential misclassification. To avoid over-adjustment, socioeconomic status (SES) was not included in the models. SES is correlated to the job you have, which correlates to exposure to job strain (46). If we included SES in the models we believe that we would adjust for some of the exposure as well. Finally, some risk of selection bias cannot be excluded. The women most affected by job strain may have been less likely to participate in the quite extensive interviews, resulting in an underrepresentation of the high-strain group. We do not expect non-participation to be a problem regarding outcomes as earlier studies have found little effect on this in the DNBC $(47,48)$.

The study is designed as a prospective cohort study with data collected before knowing the outcome. One could have done a case-control study on medically diagnosed asthma patients to have more validated endpoints, but then the exposure assessment would have been retrospective. Another approach could be sibling studies where the mothers were exposed to job strain in one pregnancy but not in the other, eliminating genetic factors as confounders. This would be at the expense of the number of participants in the study population. In construction of a new birth cohort, it would be advantageous to include a more detailed characterization of the maternal stress exposure, eg, by including more questions from Karasek's Job Content Questionnaire (41).

\section{Interpretation}

Asthma and eczema are inflammatory diseases and results of inappropriate responses of the immune system. The presented findings indicate that maternal job strain may influence development of the fetal immune system. The fact that non-genetic factors can influence the development or imprinting of physiological systems early in life is known as perinatal programming [reviewed in (49)]. Particularly the hypothalamic-pituitary-adrenocortical (HPA) axis seems susceptible to early-life programing. Disturbed regulation of the HPA axis suggest that immune functions may also be disrupted and this could have implications in the development of asthma as well as other inflammatory diseases (50).

\section{Acknowledgments}

The authors wish to thank Dr Ida Elisabeth Huitfeldt Madsen from the National Research Centre of the Working Environment, Denmark, for her valuable input to the discussion.

The Danish National Research Foundation has established the Danish Epidemiology Science Centre that initiated and created the DNBC. The cohort is furthermore a result of a major grant from this Foundation. Additional support for the DNBC is obtained from the Pharmacy Foundation, the Egmont Foundation, the March of Dimes Birth Defects Foundation, the Augustinus Foundation, and the Health Foundation. This specific study is supported by grants from the MINERVA project (www.minervanet.dk), the Danish Work Environment Research Foundation (Grant no: 20080016458/4), Aarhus University, and the Danish Graduate School in Public Health Science.

The authors declare no competing interests.

\section{References}

1. Worldwide variation in prevalence of symptoms of asthma, allergic rhinoconjunctivitis, and atopic eczema: ISAAC. The International Study of Asthma and Allergies in Childhood (ISAAC) Steering Committee. Lancet. 1998 Apr 25;351(9111):1225-32. http://dx.doi.org/10.1016/S01406736(97)07302-9.

2. Kay J, Gawkrodger DJ, Mortimer MJ, Jaron AG. The prevalence of childhood atopic eczema in a general population. J Am Acad Dermatol. 1994 Jan;30(1):35-9. http://dx.doi. org/10.1016/S0190-9622(94)70004-4.

3. Hansen TE, Evjenth B, Holt J. Increasing prevalence of asthma, allergic rhinoconjunctivitis and eczema among schoolchildren: three surveys during the period 1985-2008. Acta Paediatr. 2013 Jan;102(1):47-52.

4. Upton MN, McConnachie A, McSharry C, Hart CL, Smith $\mathrm{GD}$, Gillis CR, et al. Intergenerational 20 year trends in the prevalence of asthma and hay fever in adults: the Midspan family study surveys of parents and offspring. BMJ. 2000 Jul;321(7253):88-92. http://dx.doi.org/10.1136/ bmj.321.7253.88.

5. Stensen L, Thomsen SF, Backer V. Change in prevalence of atopic dermatitis between 1986 and 2001 among children. Allergy Asthma Proc. 2008 Jul;29(4):392-6. http://dx.doi. org/10.2500/aap.2008.29.3139.

6. Hansen EF, Rappeport Y, Vestbo J, Lange P. Increase 
in prevalence and severity of asthma in young adults in Copenhagen. Thorax. 2000 Oct;55(10):833-6. http://dx.doi. org/10.1136/thorax.55.10.833.

7. Martino D, Prescott S. Epigenetics and prenatal influences on asthma and allergic airways disease. Chest. 2011 Mar;139(3):640-7. http://dx.doi.org/10.1378/chest.10-1800.

8. Gheorghe CP, Goyal R, Mittal A, Longo LD. Gene expression in the placenta: maternal stress and epigenetic responses. Int J Dev Biol. 2010;54(2-3):507-23. http://dx.doi.org/10.1387/ ijdb.082770cg.

9. Penn AL, Rouse RL, Horohov DW, Kearney MT, Paulsen DB, Lomax L. In utero exposure to environmental tobacco smoke potentiates adult responses to allergen in BALB/c mice. Environ Health Perspect. 2007 Apr;115(4):548-55. http:// dx.doi.org/10.1289/ehp.9780.

10. Linneberg A, Petersen J, Gronbaek M, Benn CS. Alcohol during pregnancy and atopic dermatitis in the offspring. Clin Exp Allergy. 2004 Nov;34(11):1678-83. http://dx.doi. org/10.1111/j.1365-2222.2004.02101.x.

11. Vance GH, Grimshaw KE, Briggs R, Lewis SA, Mullee MA, Thornton CA, et al. Serum ovalbumin-specific immunoglobulin $\mathrm{G}$ responses during pregnancy reflect maternal intake of dietary egg and relate to the development of allergy in early infancy. Clin Exp Allergy. 2004 Dec;34(12):1855-61. http:// dx.doi.org/10.1111/j.1365-2222.2004.02111.x.

12. Vance GH, Lewis SA, Grimshaw KE, Wood PJ, Briggs RA, Thornton CA, et al. Exposure of the fetus and infant to hens' egg ovalbumin via the placenta and breast milk in relation to maternal intake of dietary egg. Clin Exp Allergy. 2005 Oct;35(10):1318-26. http://dx.doi.org/10.1111/j.13652222.2005.02346.x.

13. Thomsen SF, Ulrik CS, Kyvik KO, Sorensen TI, Posthuma D, Skadhauge LR, et al. Association between obesity and asthma in a twin cohort. Allergy. 2007 Oct;62(10):1199-204. http:// dx.doi.org/10.1111/j.1398-9995.2007.01480.x.

14. Christensen BH, Thulstrup AM, Hougaard KS, Skadhauge LR, Hansen KS, Frydenberg M, et al. Maternal occupational exposure to asthmogens during pregnancy and risk of asthma in 7-year-old children: a cohort study. BMJ Open. 2013 April;3(4).

15. Tagiyeva N, Devereux G, Semple S, Sherriff A, Henderson J, Elias P, et al. Parental occupation is a risk factor for childhood wheeze and asthma. Eur Respir J. 2010 May;35(5):987-93. http://dx.doi.org/10.1183/09031936.00050009.

16. von Hertzen LC. Maternal stress and T-cell differentiation of the developing immune system: possible implications for the development of asthma and atopy. J Allergy Clin Immunol. 2002 Jun;109(6):923-8. http://dx.doi.org/10.1067/ mai.2002.124776.

17. Quon BS, Goss CH. Maternal stress: a cause of childhood asthma? Am J Respir Crit Care Med. 2012 Jul 15;186(2):1167. http://dx.doi.org/10.1164/rccm.201205-0871ED.

18. Lin YC, Wen HJ, Lee YL, Guo YL. Are maternal psychosocial factors associated with cord immunoglobulin $\mathrm{E}$ in addition to family atopic history and mother immunoglobulin E? Clin Exp Allergy. 2004 Apr;34(4):548-54. http://dx.doi.org/10.1111/ j.1365-2222.2004.1928.x.

19. Wright RJ, Visness CM, Calatroni A, Grayson MH, Gold DR, Sandel MT, et al. Prenatal maternal stress and cord blood innate and adaptive cytokine responses in an inner-city cohort. Am J Respir Crit Care Med. 2010 Jul 1;182(1):25-33. http:// dx.doi.org/10.1164/rccm.200904-0637OC.

20. Sausenthaler S, Rzehak P, Chen CM, Arck P, Bockelbrink A, Schafer T, et al. Stress-related maternal factors during pregnancy in relation to childhood eczema: results from the LISA Study. J Investig Allergol Clin Immunol. 2009;19(6):481-7.

21. Cookson H, Granell R, Joinson C, Ben-Shlomo Y, Henderson AJ. Mothers' anxiety during pregnancy is associated with asthma in their children. J Allergy Clin Immunol. 2009 Apr;123(4):84753. http://dx.doi.org/10.1016/j.jaci.2009.01.042.

22. Fang F, Hoglund CO, Arck P, Lundholm C, Langstrom N, Lichtenstein $\mathrm{P}$, et al. Maternal bereavement and childhood asthma-analyses in two large samples of Swedish children. PLoS One. 2011 Nov;6(11). http://dx.doi.org/10.1371/ journal.pone.0027202.

23. Khashan AS, Wicks S, Dalman C, Henriksen TB, Li J, Mortensen PB, et al. Prenatal stress and risk of asthma hospitalization in the offspring: a Swedish population-based study. Psychosom Med. 2012 Jul;74(6):635-41. http://dx.doi. org/10.1097/PSY.0b013e31825ac5e7.

24. Marco R., Pesce G, Girardi P, Marchetti P, Rava M, Ricci P, et al. Foetal exposure to maternal stressful events increases the risk of having asthma and atopic diseases in childhood. Pediatr Allergy Immunol. 2012 Dec;23(8):724-9. http://dx.doi. org/10.1111/j.1399-3038.2012.01346.x.

25. Wang IJ, Wen HJ, Chiang TL, Lin SJ, Chen PC, Guo YL. Maternal employment and atopic dermatitis in children: a prospective cohort study. Br J Dermatol. 2013 Apr;168(4):794 801. http://dx.doi.org/10.1111/bjd.12195.

26. Karasek RA. Job Demands, Job Decision Latitude, and Mental Strain: Implications for Job Redesign. Administrative Science Quarterly. 1979;24:285-308. http://dx.doi. org/10.2307/2392498.

27. Olsen J, Melbye M, Olsen SF, Sorensen TI, Aaby P, Andersen AM, et al. The Danish National Birth Cohort--its background, structure and aim. Scand J Public Health. 2001 Dec;294:300 7. http://dx.doi.org/10.1177/14034948010290040201.

28. Karasek RA, Theorell T. Healthy work: stress, productivity, and the reconstruction of working life. New York: Basic Books; 1990.

29. Kennedy SM, Le MN, Choudat D, Kauffmann F. Development of an asthma specific job exposure matrix and its application in the epidemiological study of genetics and environment in asthma (EGEA). Occup Environ Med. 2000 Sep;57(9):63541. http://dx.doi.org/10.1136/oem.57.9.635.

30. Strachan DP. Hay fever, hygiene, and household size. BMJ. 1989 Nov;299(6710):1259-60. http://dx.doi.org/10.1136/ bmj.299.6710.1259.

31. Romagnani S. The increased prevalence of allergy and the hygiene hypothesis: missing immune deviation, reduced immune suppression, or both? Immunology. 2004 Jul;112(3):352-63. http://dx.doi.org/10.1111/j.1365-2567.2004.01925.x. 
32. Asher MI, Keil U, Anderson HR, Beasley R, Crane J, Martinez F, et al. International Study of Asthma and Allergies in Childhood (ISAAC): rationale and methods. Eur Respir J. 1995 Mar;8(3):483-91. http://dx.doi.org/10.1183/09031936. 95.08030483 .

33. Hougaard KS, Hansen AM. Enhancement of developmental toxicity effects of chemicals by gestational stress. A review. Neurotoxicol Teratol. 2007 Jul;29(4):425-45. http://dx.doi. org/10.1016/j.ntt.2007.02.003.

34. Kivimaki M, Gimeno D, Ferrie JE, Batty GD, Oksanen T, Jokela M, et al. Socioeconomic position, psychosocial work environment and cerebrovascular disease among women: the Finnish public sector study. Int J Epidemiol. 2009 Oct;38(5):1265-71. http://dx.doi.org/10.1093/ije/dyn373.

35. Trudel X, Brisson C, Milot A. Job strain and masked hypertension. Psychosom Med. 2010 Oct;72(8):786-93. http://dx.doi.org/10.1097/PSY.0b013e3181eaf327.

36. Slopen N, Glynn RJ, Buring JE, Lewis TT, Williams DR, Albert MA. Job strain, job insecurity, and incident cardiovascular disease in the Women's Health Study: results from a 10-year prospective study. PLoS One. 2012 Jul;7(7). http://dx.doi.org/10.1371/journal.pone.0040512.

37. Juhl M, Andersen PK, Olsen J, Andersen AM. Psychosocial and physical work environment, and risk of pelvic pain in pregnancy. A study within the Danish national birth cohort. J Epidemiol Community Health. 2005 Jul;59(7):580-5. http:// dx.doi.org/10.1136/jech.2004.029520.

38. Larsen AD, Hannerz H, Juhl M, Obel C, Thulstrup AM, Bonde JP, et al. Psychosocial job strain and risk of adverse birth outcomes: a study within the Danish national birth cohort. Occup Environ Med. 2013 Dec;70(12):845-51. http://dx.doi. org/10.1136/oemed-2013-101453.

39. Zhu JL, Hjollund NH, Andersen AM, Olsen J. Shift work, job stress, and late fetal loss: The National Birth Cohort in Denmark. J Occup Environ Med. 2004 Nov;46(11):1144-9. http://dx.doi.org/10.1097/01.jom.0000145168.21614.21.

40. Karasek R. The political implications of psychosocial work redesign: a model of the psychosocial class structure. Int J Health Serv. 1989;19:481-508. http://dx.doi. org/10.2190/66AM-Q4PF-PUHK-5BT1.
41. Dept of Work Environment, University of Massachusetts. The Job Content Questionnaire. Lowell (MA): University of Massachusetts; 2012. http://www jcqcenter org

42. Littman AJ, White E, Satia JA, Bowen DJ, Kristal AR. Reliability and validity of 2 single-item measures of psychosocial stress. Epidemiology. 2006 Jul;17(4):398-403. http://dx.doi.org/10.1097/01.ede.0000219721.89552.51.

43. Kuper H, Marmot M. Job strain, job demands, decision latitude, and risk of coronary heart disease within the Whitehall II study. J Epidemiol Community Health. 2003 Feb;57(2):14753. http://dx.doi.org/10.1136/jech.57.2.147.

44. Mikkelsen S, Bonde JP, Andersen JH. Analysis of job strain effects. Occup Environ Med. 2011 Oct;68(10):786. http:// dx.doi.org/10.1136/oemed-2011-100203.

45. Benn CS, Benfeldt E, Andersen PK, Olesen AB, Melbye M, Bjorksten B. Atopic dermatitis in young children: diagnostic criteria for use in epidemiological studies based on telephone interviews. Acta Derm Venereol. 2003;83(5):347-50. http:// dx.doi.org/10.1080/00015550310006563.

46. Llorens C, Alos R, Cano E, Font A, Jodar P, Lopez V, et al. Psychosocial risk exposures and labour management practices. An exploratory approach. Scand J Public Health. 2010 Feb;38(3 Suppl):125-36. http://dx.doi. org/10.1177/1403494809354363.

47. Greene N, Greenland S, Olsen J, Nohr EA. Estimating bias from loss to follow-up in the Danish National Birth Cohort. Epidemiology. 2011 Nov;22(6):815-22.

48. Nohr EA, Frydenberg M, Henriksen TB, Olsen J. Does low participation in cohort studies induce bias? Epidemiology. $2006 \mathrm{Jul} ; 17(4): 413-8$. http://dx.doi.org/10.1097/01. ede.0000220549.14177.60.

49. Welberg LA, Seckl JR. Prenatal stress, glucocorticoids and the programming of the brain. J Neuroendocrinol. 2001 Feb;13(2):113-28. http://dx.doi.org/10.1111/j.13652826.2001.00601.x.

50. Wright RJ. Stress and childhood asthma risk: overlapping evidence from animal studies and epidemiologic research. Allergy Asthma Clin Immunol. 2008 Mar 15;4(1):29-36. http://dx.doi.org/10.1186/1710-1492-4-1-29.

Received for publication: 23 January 2014 